\title{
Recursos hídricos em São José do Rio Preto
}

\author{
Water resources in São José do Rio Preto
}

Recursos hídricos en São José do Rio Preto

\section{Resumo}

A demanda por água tornou-se crescente em decorrência do aumento populacional e do desenvolvimento agroindustrial. $\mathrm{O}$ aumento pela demanda hídrica gera uma maior exploração dos mananciais subterrâneos, visto que muitas fontes superficiais são incapazes de atender a demanda requerida. No trabalho avaliou-se a destinação do uso da água subterrânea, dos poços perfurados no município de São José do Rio Preto, nas décadas de 1950, 1960, 1970, 1980, 1990, 2000 e 2010. Foram utilizadas informações de vazão, profundidade, data e tipo de uso da água de 801 poços. Os dados foram coletados no DAEE (Departamento de Água e Energia Elétrica) de Araraquara e no SIAGAS (Sistema de Informações de Águas Subterrâneas). Os resultados demonstraram que o maior número de perfurações de poços, no município, se destinou ao uso doméstico e ao abastecimento público.

Palavras-chave: Gerenciamento; Abastecimento público; Demanda hídrica.

\begin{abstract}
The demand for water has become growing due to population increase and agro-industrial development. The increased by demand generates further exploration of the underground watersheds, since many superficial sources are unable to meet the demand required. At work we evaluated the destination of use of groundwater, of the wells drilled in the municipality of São José do Rio Preto, in the 1950, 1960, 1970, 1980, 1990, 2000 and 2010. Was used info flow, depth, date and type of water use of 801 wells. Data were collected in the DAEE (Department of Water and Electrical Energy) and in the SIAGAS (System Information Groundwater). The results showed that the largest number of drilling wells, in the municipality, was destined to the domestic and public supply.
\end{abstract}

Keywords: Management; Public supply; Water demand.

\section{Resumen}

La demanda de agua ha crecido como resultado del crecimiento de la población y el desarrollo agroindustrial. El aumento de la demanda de agua genera una mayor explotación de las fuentes subterráneas, ya que muchas fuentes superficiales no pueden satisfacer la demanda requerida. El estudio evaluó el uso de agua subterránea de pozos perforados en la ciudad de São José do Rio Preto, en las décadas de 1950, 1960, 1970, 1980, 1990, 2000 y 2010. Fecha y tipo de uso de agua de 801 pozos. Los datos fueron recolectados en el DAEE (Departamento de Agua y Energía Eléctrica) de Araraquara y en SIAGAS (Sistema de Información de Aguas Subterráneas). Los resultados 
mostraron que la mayor cantidad de perforaciones de pozos en la ciudad se destinó al uso doméstico y al suministro público.

Palabras clave: Gestión; Abastecimiento público; Demanda de agua.

\section{Introdução}

A utilização de mananciais subterrâneos para suprimento da demanda por água torna-se cada vez mais crescente nos municípios brasileiros. Conforme informações da Agência Nacional das Águas (ANA, 2010a), cerca de 2.153 ou $39 \%$ dos municípios são abastecidos exclusivamente por águas subterrâneas. No Estado de São Paulo mais de $80 \%$ das cidades são abastecidas parcial ou totalmente por água subterrânea (CETESB, 2009).

Na Unidade de Gerenciamento de Recursos Hídricos (UGRHI 15) do Comitê de Bacia Hidrográfica Turvo/Grande, 57 dos 64 municípios que a compõem, utilizam exclusivamente água subterrânea para abastecimento público (IPT, 2009). O município de São José do Rio Preto apresentou o maior índice de consumo de água da UGRHI em 2011, no montante de $1,2346 \mathrm{~m}^{3} / \mathrm{s}$.

Nesse município, 43\% da água destinada ao abastecimento público, provêm de manancial subterrâneo (ANA, 2010b). Cerca de 73,46\% das fontes de captação de água da cidade são de subsuperficie, e 26,54\% corresponde a captação superficial no Rio Preto (CONJUNTURA ECONÔMICA, 2011). Os poços perfurados em São José do Rio Preto captam água do Sistema Aquífero Bauru e das formações Botucatu/Pirambóia (Aquífero Guarani) (Barcha, 2000).

Alguns municípios paulistas, como São José do Rio Preto, Capivari, Rafard, Indaiatuba e Ribeirão Preto, enfrentam problemas de disponibilidade hídrica, provenientes da explotação excessiva de água subterrânea e da elevada quantidade de poços produtores (Iritani e Ezaki, 2008; DAEE/IG/IPT/CPRM, 2005; Iritani et. al., 2011). Os poços perfurados no Aquífero Bauru, na cidade de São José do Rio Preto, apresentam rebaixamento dos níveis estáticos, implicando na diminuição da produtividade do poço e da capacidade hídrica do manancial (Oliveira, 2002).

Em decorrência da ameaça de diminuição do volume de água disponível nas fontes superficiais dos recursos hídricos, decorrente de aspectos qualitativos e quantitativos, o sistema de abastecimento público investe nas captações de água subterrânea.

Desde 1950 houve preocupação com a demanda para o abastecimento público do município de São José do Rio Preto - SP, iniciando-se perfurações de poços para garantir o abastecimento de água (SeMAE, 2008).

De acordo com Llamas e Martinez-Santos (2005) a principal causa dos problemas hídricos mundiais no sistema de abastecimento público decorre do uso intensivo dos recursos hídricos; do gerenciamento desassociado das águas superficiais e subterrâneas, e do desenvolvimento sócio-econômico.

Connor, Cox e Lohani, (2007), descreveram que nos estados do oeste dos Estados Unidos, a seca foi o motivo principal de problemas no abastecimento público, causando rebaixamento do volume de água armazenado em barragens, condicionando a exploração de mananciais subterrâneos.

Segundo Todd e Mays (2005), o aumento da urbanização reduz a área de recarga dos aquíferos e proporcionam uma diminuição nas condições de infiltração. Este fenômeno reflete sob o potencial hídrico do manancial subterrâneo, ocasionando insegurança no sistema de abastecimento público.

Para reduzir os impactos sob os recursos hídricos subterrâneos, a taxa de extração deve respeitar a capacidade de recarga do aquífero, não a excedendo. Uma maneira que possibilita a racionalização do uso da água no abastecimento público pode ser o aumento de sua tarifação (Berrittella et. al., 2007).

Com relação ao sistema de abastecimento de água no município de São José do Rio Preto, em meados das décadas de 80 e 90, fatores como a localização do principal sistema produtor associado ao assoreamento das represas, causaram problemas 
no abastecimento de água do município, condicionando a um aumento na explotação de água subterrânea (SeMAE, 2008).

O objetivo do estudo foi analisar os tipos de usuários da água subterrânea no município de São José do Rio Preto, enfatizando a evolução da instalação de poços destinados ao abastecimento público e ao abastecimento doméstico, no período de 1950 a 2010.

\section{Metodologia}

\section{Área de estudo}

O município de São José do Rio Preto está situado na região noroeste do Estado de São Paulo, entre as coordenadas 2049'11' ' de latitude Sul e 49²2’46”' de longitude Oeste. Ocupa uma área territorial de $431 \mathrm{~km}^{2}$ (IBGE, 2010), sendo 123 km² a porção urbanizada, contabilizada em 2012. Comporta uma população de 407.816 habitantes, dos quais 24.741 habitantes residem na área rural (SEADE, 2021).

Na Figura 1 é mostrada a localização do município de São José do Rio Preto, o qual faz divisa a oeste com Mirassol, a leste com Guapiaçu, ao norte com Ipiguá e Onda Verde e ao sul com Bady Bassitt e Cedral. O município pertence à Unidade de Gerenciamento de Recursos Hídricos da Bacia do Turvo/Grande (UGRHI 15), $4^{\text {a }}$ maior UGRHI do estado de São Paulo, estando inserido na sub-bacia do Rio Preto.

Figura 1 - Localização do município de São José do Rio Preto no Estado de São Paulo.

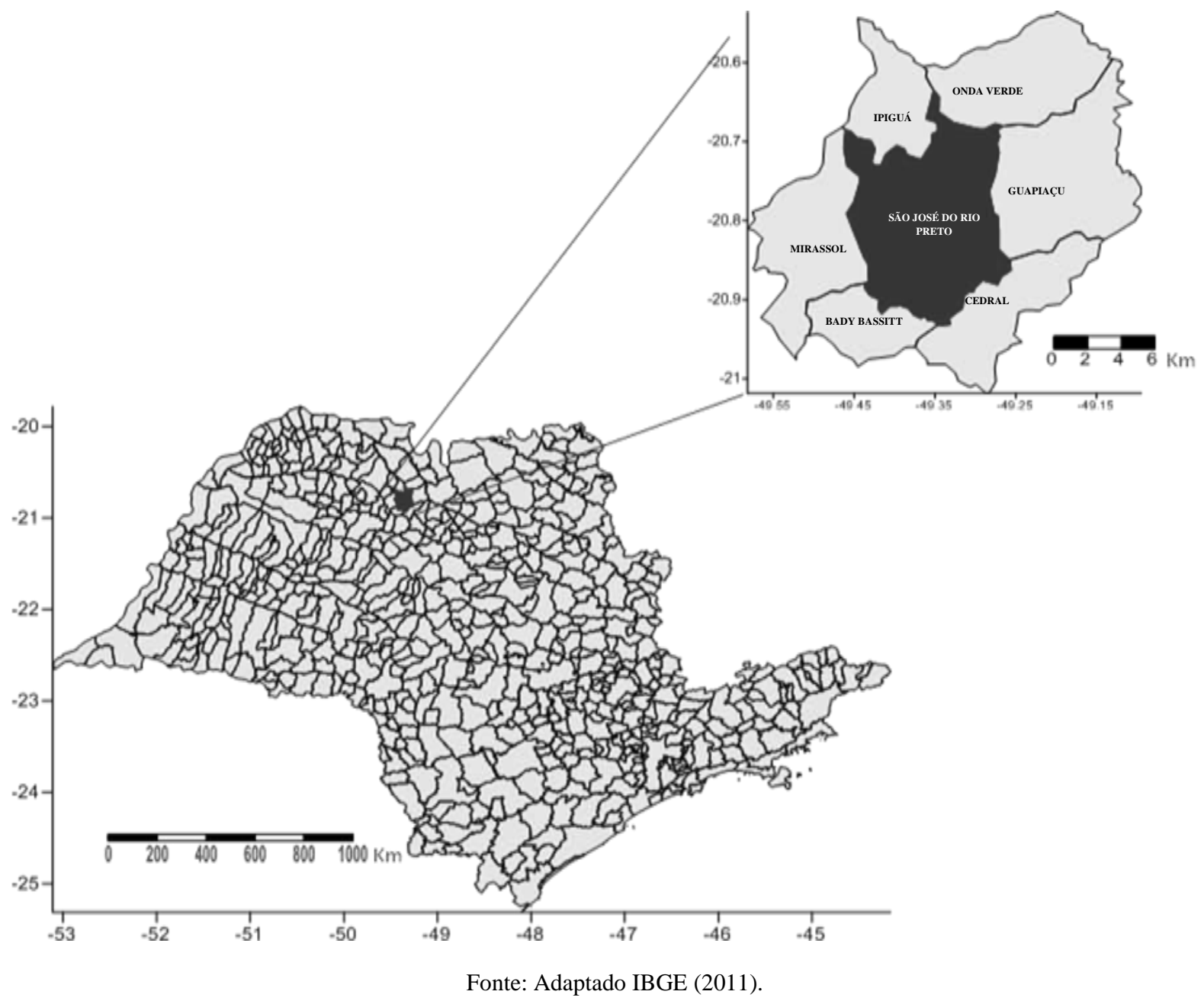


A principal drenagem fluvial ocorre pelo Córrego Rio Preto, do qual deriva-se o nome do município. Este córrego contribui com parte do abastecimento da cidade utilizando-se para tal uma represa municipal nele construída.

O clima caracteriza-se por temperaturas médias anuais que variam entre 23 e $26^{\circ} \mathrm{C}$, com máximas anuais de 29 a $33^{\circ} \mathrm{C}$ e as mínimas anuais ficam na faixa de 16 a $20^{\circ} \mathrm{C}$, enquadrando-se em dois tipos climáticos da classificação de Koeppen, o tropical úmido com inverno seco (Aw) e o quente úmido com estação seca, com verão quente e inverno não muito frio (Cwa). A precipitação apresenta comportamento variável de 1049 a $1593 \mathrm{~mm}$ ao longo do tempo.

\section{Avaliação da utilização da água subterrânea}

Para analisar o uso da água subterrânea no município de São José do Rio Preto, foram coletadas informações de poços catalogados em duas bases de dados, no SIAGAS e no DAEE de Araraquara.

Os dados coletados foram comparados e conferidos criteriosamente pelas coordenadas geográficas, tendo em vista alguns poços estarem catalogados nas duas bases de dados, bem como algumas coordenadas estarem inseridas fora da região do município. Utilizou-se na pesquisa informações dos poços que captam água no Aquífero Bauru e no Serra Geral, sendo excluídos aqueles que exploram outro sistema aquífero.

Ao final da seleção, totalizaram-se 801 poços e, com o auxílio do software Microsof Excel os dados foram organizados de acordo com os parâmetros analisados (data de perfuração/instalação do poço, profundidade e vazão dos mesmos e tipo de uso da água após instalação). Foi realizada uma organização dos dados por década de perfuração, critério utilizado para avaliar os parâmetros em épocas distintas, no período de 1950 a 2010 (correspondendo aos anos de 2010 e 2011). Para apresentação visual dos resultados, utilizou-se o Microsoft Excel, na construção dos gráficos.

É altamente recomendado que os dados aqui avaliados sejam abordados em novos trabalhos considerando o Censo 2022 e valores de explotação atualizados para o mesmo ano, para se ter a exatidão das condições de uso dos recursos hídricos da região nos últimos anos.

\section{Resultados e Discussão}

Verificou-se, diversos tipos de usos para a água subterrânea captada no município de São José do Rio Preto, como público/urbano (poços do SeMAE e da prefeitura), doméstico/comercial (poços em chácaras, lojas, postos de combustível, residências e condomínios), industrial, para irrigação e outros.

O uso preponderante do município representado por 39\% do total (314 poços) é o abastecimento doméstico/comercial, seguido pelo abastecimento público/urbano com 26\% (205 poços). Os demais usos correspondem a 35\% (282 poços) (Figura 2).

Figura 2 - Porcentagem de utilização dos poços no município de São José do Rio Preto.

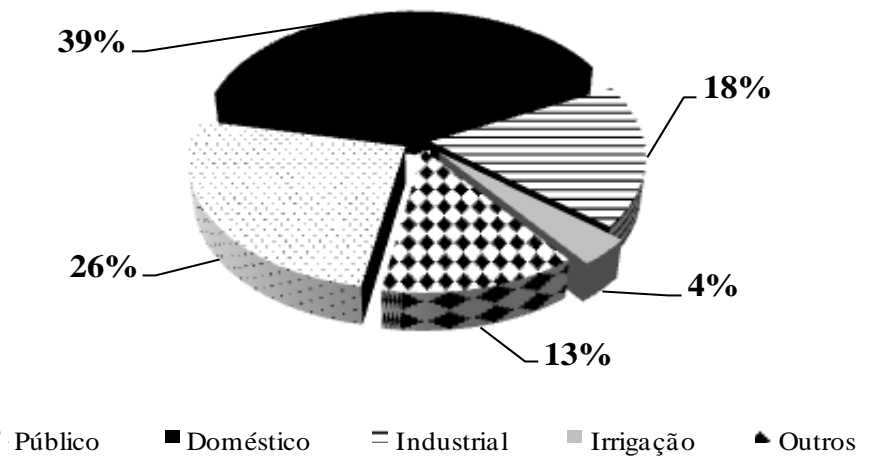

Fonte:Autores. 
O aumento das perfurações destinadas ao abastecimento doméstico, na última década deve-se, dentre outros fatores, ao fato do SeMAE não se responsabilizar pelo fornecimento de água aos novos loteamentos e empreendimentos. Assim, na ausência de disponibilidade técnica, econômica e financeira, a responsabilidade da operação e manutenção do sistema de abastecimento será dos novos usuários, conforme Art. 130 do Decreto nº 13.265 de 2006.

A evolução das perfurações por tipo de uso da água, em décadas, está representada na Figura 3 . Na década de 1950 havia o registro de somente 5 poços, sendo 4 destinados ao abastecimento público, e 1 ao abastecimento doméstico. Na década de 1960 surgiram poços direcionados ao uso industrial e outras formas, mas a utilização da água subterrânea na irrigação ocorreu apenas na década de 1970. A década de 2000 apresentou o maior número de perfurações, com 397 poços, e observa-se que os abastecimentos domésticos e industriais lideram as formas de utilização.

$\mathrm{O}$ aumento das perfurações direcionadas ao abastecimento doméstico, embora condicionadas pelo Decreto $\mathrm{n}^{\circ} 13.265$ somente a partir de 2006, lideram o ranking de perfurações desde a década de 1980. Este destaque acentuado pode ser explicado pela tarifação do serviço de abastecimento, que não ocorre no uso doméstico, sendo os principais usuários catalogados neste uso os estabelecimentos comerciais, condomínios, chácaras, clubes e postos de combustível.

Figura 3 - Poços perfurados no município de São José do Rio Preto.

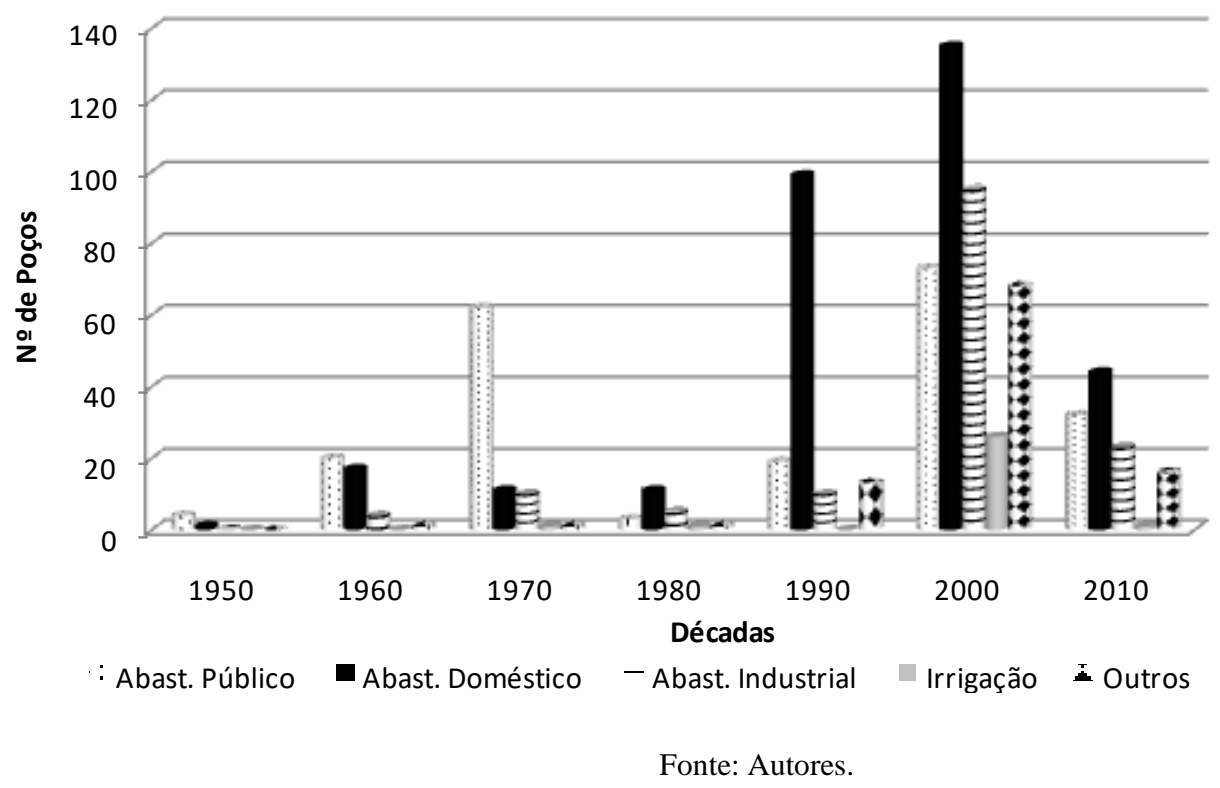

Observando a quantidade das perfurações destinadas ao abastecimento público e ao abastecimento doméstico, nota-se que nas décadas de 1950 e 1960 havia pouca diferença entre esses tipos de uso, que equivalia a quantidade de 3 poços a mais destinados ao abastecimento público. Na década de 1970, o abastecimento público apresentou 62 novas perfurações, destacando-se em relação às 11 perfurações do uso doméstico, contudo a partir da década de 1990 o surgimento das perfurações destinadas ao abastecimento doméstico foram superiores às do abastecimento público (Figura 4). 
Figura 4 - Crescimento do abastecimento público $\mathrm{X}$ abastecimento doméstico.

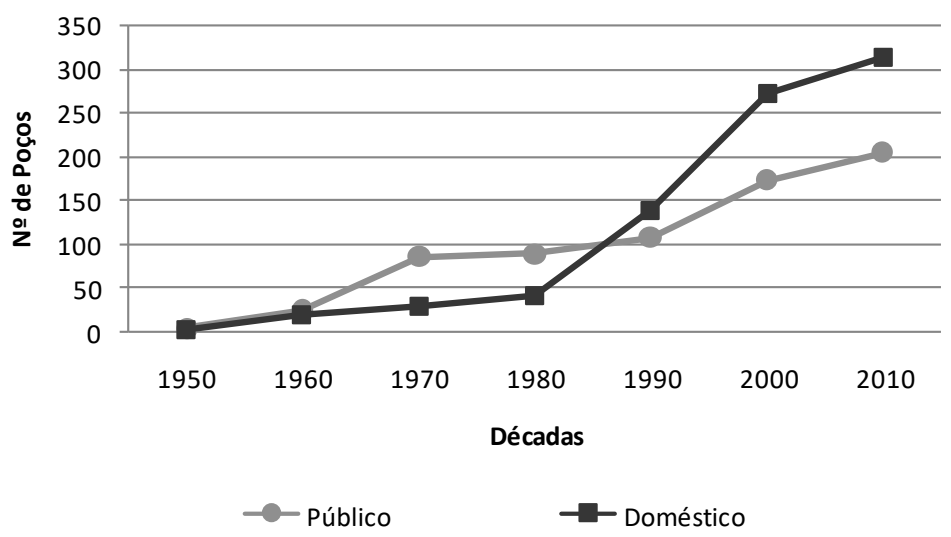

Fonte: Autores.

Um fator que pode ter contribuído para o aumento das perfurações destinadas ao abastecimento doméstico, é a tarifação do abastecimento público, tarifa de água cobrada pelo SeMAE (Serviço Municipal Autônomo de Água e Esgoto), visto que os proprietários de poços outorgados no uso doméstico, não pagam pelo uso da água.

Analisando os tipos de utilização da água e as profundidades desses poços, verifica-se que as classes mais profundas (231-300m e 301-370m) não englobam poços com a finalidade de utilização industrial, irrigação e demais usos, sendo perfurados apenas para suprir as demandas de abastecimento público/urbano e doméstico/comercial (Figura 5).

A grande quantidade de poços em profundidades mais rasas pode ser explicada pela facilidade de construção, associada ao menor custo de perfuração e instalação. Dessa maneira muitos proprietários quando necessitam maior volume de água, preferem fazer dois poços mais rasos ao invés de um poço mais profundo.

O abastecimento público/urbano apresentou a maior concentração de poços na classe de profundidade entre 91-160m (109 poços), enquanto que no abastecimento doméstico/comercial a classe predominante foi entre 20-90m (161 poços), já no abastecimento industrial estas classes dividem-se igualmente. Nesta análise utilizou-se 718 poços que apresentaram informação de profundidade.

Figura 5 - Tipo de utilização das captações de água por classes de profundidade.

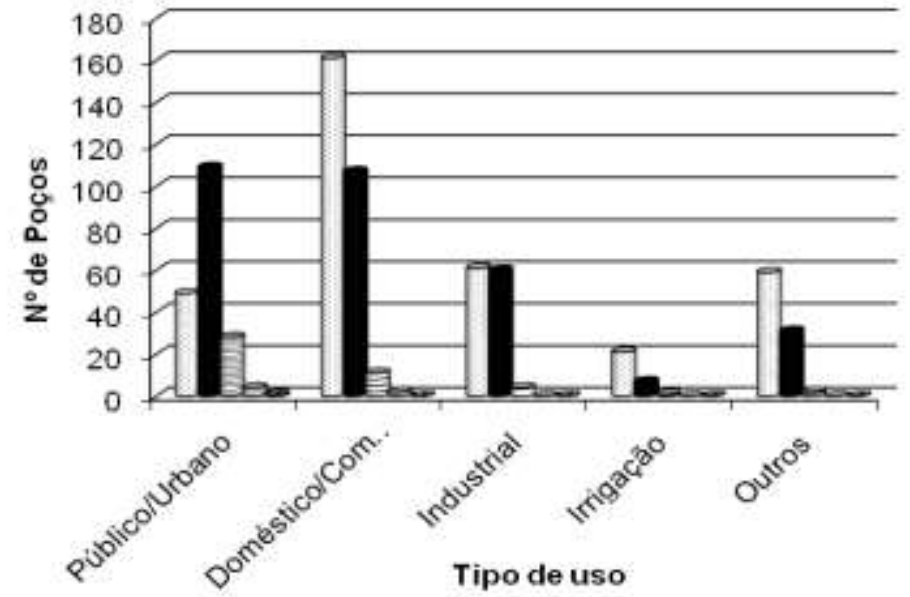


A variabilidade das perfurações destinadas ao abastecimento público, doméstico e industrial se deve a vazão requerida por cada usuário de determinada classe de uso, pois quanto mais profundo o poço maior a possibilidade do volume de água captado, podendo ser explorado mais de um aquífero.

A vazão total explotada dos aquíferos Bauru e Serra Geral no município de São José do Rio Preto pelos 725 poços com informações de vazão e período de bombeamento é 64.113 m³/d. Cerca de $47 \%$ (30.303 m³/d) da vazão captada por 145 poços é destinada ao abastecimento público, enquanto o abastecimento doméstico representa $32 \%\left(20.149 \mathrm{~m}^{3} / \mathrm{d}\right) \mathrm{com} 298$ poços em funcionamento. Os demais tipos de utilização somam $21 \%(13.487$ m³/d) (Figura 6).

Figura 6 - Vazão explotada no município de São José do Rio Preto.

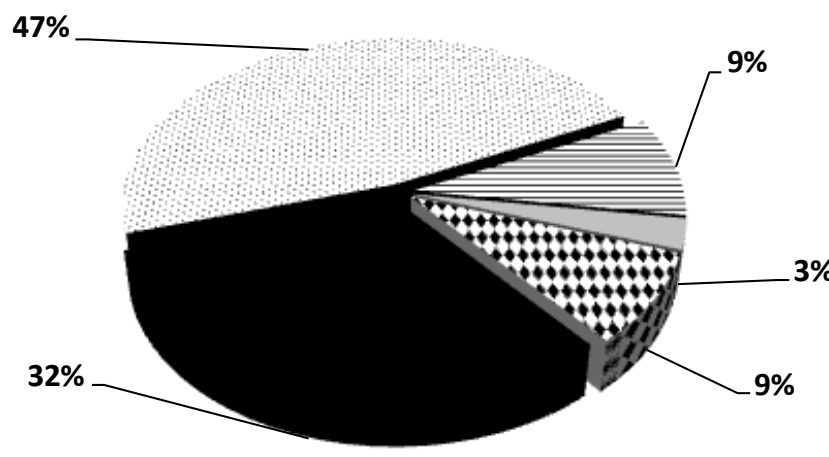

- Abast. Doméstico : Abast. Público - Abast. Industrial $\quad$ Irrigação : Outros

Fonte: Autores.

Pela análise da vazão explotada no município, nota-se que o abastecimento público representa, quantitativamente, o principal usuário da água subterrânea, desta maneira na ocorrência de um déficit hídrico, o sistema de abastecimento urbano poderá enfrentar sérios problemas.

Nota-se que o abastecimento doméstico lidera o número de perfurações, entretanto mesmo em menor quantidade, a maior porção do volume de água retirado dos Aquíferos Bauru e Serra Geral, destina-se ao abastecimento público (Figura 7).

A problemática no sistema de abastecimento público da cidade, conforme SeMAE (2008), ocorrida entre as décadas de 1980 e 1990, pode ter proporcionado o aumento da vazão utilizada para o abastecimento doméstico, quase se igualando a vazão destinada ao uso público na década de 90, conforme ilustrado na Figura 7. 
Figura 7 - Vazão acumulada pelo abastecimento público e doméstico com o passar das décadas.

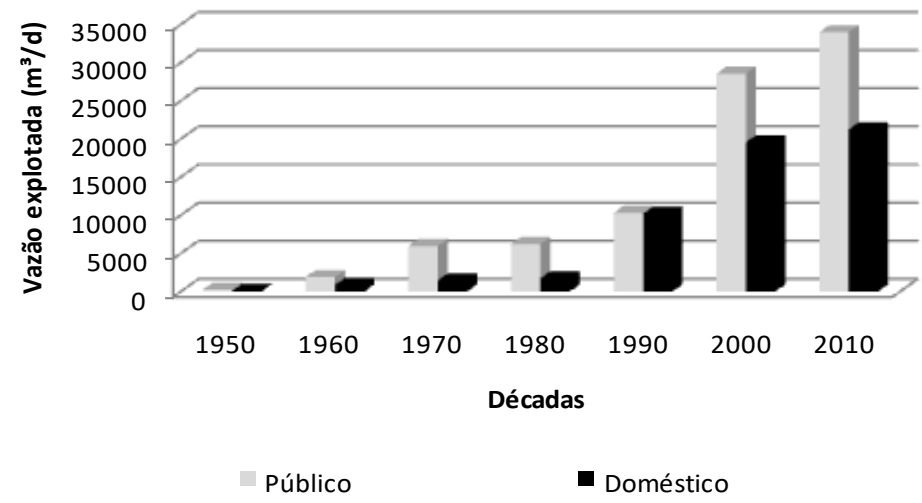

Fonte: Autores.

Percebe-se que o crescimento populacional tem influência no aumento da demanda para o abastecimento público do município de São José do Rio Preto, como pode ser visto nas Figuras 8 e 9, influenciando também na demanda para o abastecimento doméstico. Contudo o abastecimento público apresentou uma correlação mais forte com o crescimento populacional em relação ao abastecimento doméstico, conforme ilustrado na Figura 9.

O fato de o abastecimento doméstico apresentar um grau de correlação menor que o abastecimento público, se deve a influência de mais variáveis no uso doméstico, visto que se destinam a postos de combustível, novos condomínios, comércio, ou seja, variando no aspecto socioeconômico.

Figura 8 - Vazão explotada pelo abastecimento público em função do aumento populacional.

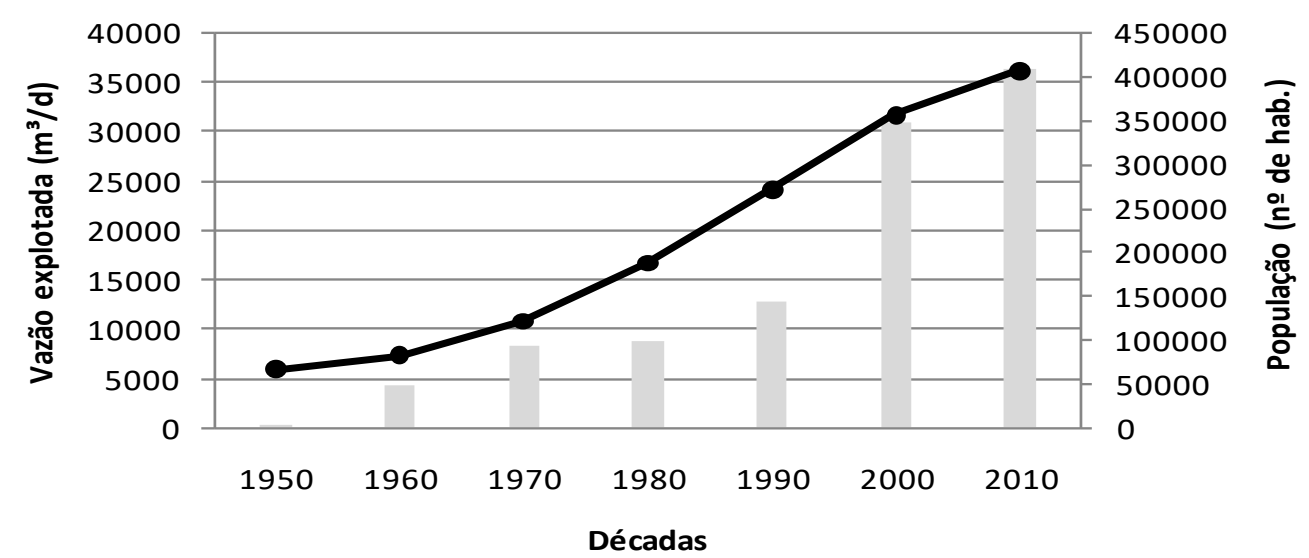

vazão explotada $\left(\mathrm{m}^{3} / \mathrm{d}\right)$

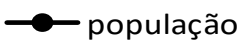

Fonte: Autores. 
Figura 9 - Correlação entre o crescimento populacional e a vazão explotada para o abastecimento público e o doméstico no período de 1950 a 2011.

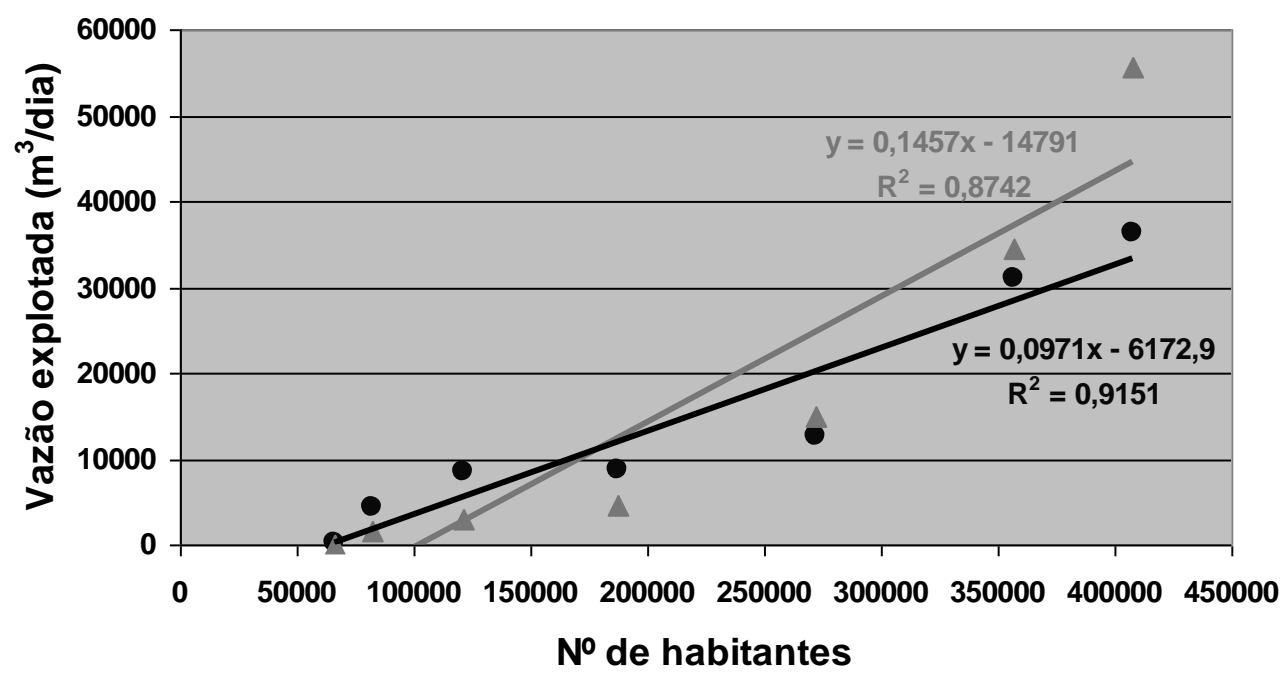

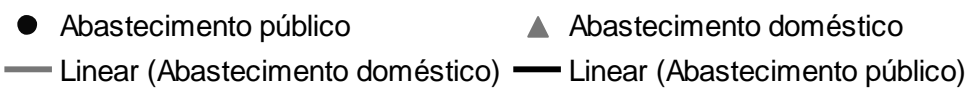

Fonte: Autores.

O volume de água demandado pelo município é obtido das seguintes fontes: os mananciais subterrâneos (Aquífero Bauru, Serra Geral e Guarani) e o manancial superficial (Rio Preto). Um aumento na vazão demandada implicará em uma maior extração de água das fontes subterrâneas, pelo fato destas fontes apresentarem maior volume disponível.

Na Figura 10 observa-se uma comparação entre as fontes de abastecimento de água de São José do Rio Preto, superficial e subterrânea.

A redução no volume superficial produzido nos anos de 2004 e 2005 pode ter sido relacionada com problemas no sistema de abastecimento, porém foi compensado com o volume produzido das fontes subterrâneas, conforme se observa na Figura 10. Já os decréscimos ocasionados a partir de 2007 do volume superficial, podem estar relacionados com a diminuição do volume útil das represas municipais por processos de assoreamento. 
Figura 10 - Fontes de abastecimento público do município de São José do Rio Preto.

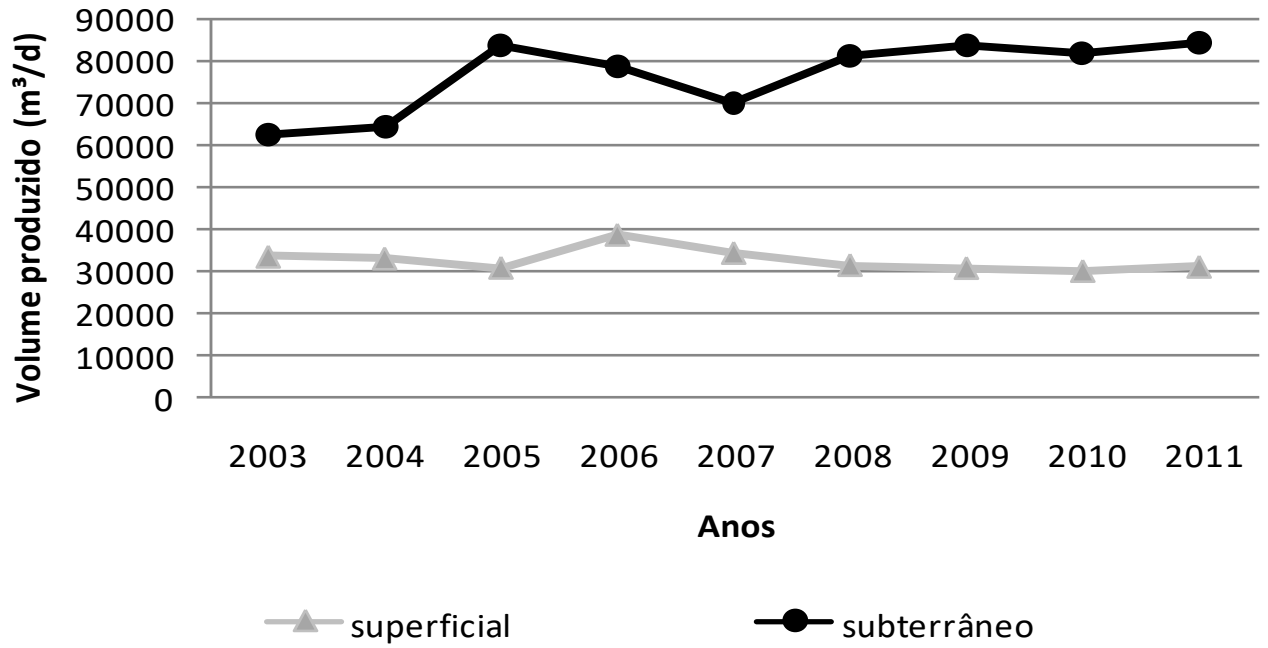

Fonte: Autores.

\section{Conclusão}

Dentre os diversos tipos de uso da água subterrânea no município de São José do Rio Preto, se destacaram os usos para o abastecimento público, no volume de água explotado e abastecimento doméstico no número de perfurações de poços.

O abastecimento público embora represente a maior utilização da água na cidade, demonstrou uma menor evolução do número de perfurações em relação ao abastecimento doméstico a partir da década de 1980. Esse fato pode ter decorrido da tarifação do serviço de abastecimento de água cobrada pelo SeMAE, da qual os proprietários de poços outorgados no uso doméstico estão isentos, como da facilidade de perfuração e instalação de poços pouco profundos.

O fato de existir uma forte correlação entre o crescimento populacional e o aumento da vazão explotada para o abastecimento de água do município, indica que medidas de gerenciamento da utilização da água são necessárias, como a tarifação do uso para o abastecimento doméstico.

\section{Referências}

ANA. (2010a) Agência Nacional das Águas. Atlas Brasil: abastecimento urbano de água: panorama nacional. Brasília: ANA.

ANA. (2010b) Agência Nacional das Águas. Atlas Brasil: abastecimento urbano de água: resultados por estado. Brasília: ANA: Engecorps/Cobrape.

Barcha, S. F. (2000) Água e abastecimento urbano em São José do Rio Preto, S.P. In: X CONGRESSO BRASILEIRO DE ÁGUAS SUBTERRÂNEAS, São Paulo. Anais... São Paulo: ABAS. 11 p.

Berrittella, M. et. al. (2007) The economic impact of restricted water supply: a computable general equilibrium analysis. Water research, n.41, p.1799-1813.

CETESB. (2009) Companhia de Tecnologia de Saneamento Ambiental, Governo do Estado de São Paulo. Secretaria de Estado de Meio Ambiente. Relatório de qualidade das águas subterrâneas do Estado de São Paulo - 2009. São Paulo: CETESB.

CONJUNTURA ECONÔMICA DE SÃO JOSÉ DO RIO PRETO. (2011) Organizada por Orlando José Bolçone, coordenada por Emília Maria Martins de Toledo Leme. 26 ed. São José do Rio Preto: Secretaria Municipal de Planejamento Estratégico, Ciência, Tecnologia e Inovação.

Connor, J. B.; Cox, W. E. \& Lohani, V. K. (2007) Public water supply in the United States: trends in surface storage capacity. In: WORLD ENVIRONMENTAL AND WATER RESOURCES CONGRESS, Tampa. Anais... Tampa: Curran Associates, 6839 p.

DAEE. (2005) Departamento de Águas e Energia Elétrica, Governo do Estado de São Paulo, Secretaria de Estadual de Recursos Hídricos. IG. Instituto Geológico, Secretaria do Meio Ambiente. IPT. Instituto de Pesquisas Tecnológicas. CPRM. Companhia de Pesquisa de Recursos Minerais, Serviço Geológico do Brasil. Mapa de Águas Subterrâneas do Estado de São Paulo. Escala: 1: 1.000.000 / Rocha, G. A. (Coord. Geral). São Paulo, Conselho Estadual de Recursos Hídricos. 
Research, Society and Development, v. 10, n. 11, e396101119806, 2021 (CC BY 4.0) | ISSN 2525-3409 | DOI: http://dx.doi.org/10.33448/rsd-v10i11.19806

IBGE (2010) - Instituto Brasileiro de Geografia e Estatística: <http://www.ibge.gov.br/home/estatistica/populacao/censo2010/default_uf.shtm>. Censo demográfico. Acesso em: 13 dez. 2020.

IPT. (2009) Instituto de Pesquisas Tecnológicas, Governo do Estado de São Paulo. Secretaria de Estado de Meio Ambiente. Plano de bacia da unidade de gerenciamento de recursos hídricos da bacia do Turvo/Grande - 2009. São Paulo, 318 p. (Relatório Técnico 397).

Iritani, M. A.\& Ezaki, S. (2008) As águas subterrâneas do Estado de São Paulo. São Paulo: SMA, 104 p.

Iritani, M. A. et. al. (2011) Projeto ambiental estratégico aquíferos: síntese das atividades período 2007/2010. São Paulo: Instituto Geológico, 134 p.

Llamas, M. R.\& Martinez-Santos, P. (2005) Intensive groundwater use: silent revolution and potential source of social conflicts. Journal of Water Resources Planning and Management, Spain, p.337-342.

Oliveira, J. N. (2002) Ferramental de gestão de águas subterrâneas para a cidade de São José do Rio Preto, SP. 127 f. Tese (Doutorado em Hidráulica e Saneamento) - Universidade de São Paulo, São Carlos.

SÃO JOSÉ DO RIO PRETO. (2006) Prefeitura Municipal. Câmara Municipal. Decreto Nº 13265 - de 08 de agosto de 2006 . Institui novo regulamento dos serviços públicos de águas e esgoto prestados pelo SeMAE. Publicada e arquivada pelo Departamento de Atividades Auxiliares do Gabinete do Prefeito.

SEADE (2021) - Fundação Sistema Estadual de Análise de Dados: <http://www.seade.gov.br/>. Acesso em: 6 fev. 2021.

SeMAE (2008) Serviço Municipal Autônomo de Água e Esgoto. Plano Diretor do Sistema de Abastecimento de Água de São José do Rio Preto. Consórcio Planágua, $224 \mathrm{p}$.

Todd, D. K. \& Mays, L. W. (2005) Groundwater Hydrology. 3 ed. Hoboken: John Wiley \& Sons, Inc. 636 p. 